\begin{tabular}{cc|c}
\hline Tar. Bil. Der. & Tarm Bilimleri Dergisi & Journal of Agricultural Sciences \\
& $\begin{array}{c}\text { Dergi web sayfası: } \\
\text { www.agri.ankara.edu.tr/dergi }\end{array}$ & Journal homepage: \\
& www.agri.ankara.edu.tr/journal
\end{tabular}

\title{
Aflatoxin Contamination in Hazelnut Oil Obtained from Hazelnuts Containing High Levels of Aflatoxin
}

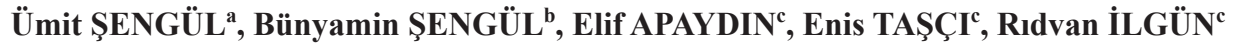 \\ ${ }^{a}$ Giresun University, Faculty of Education, Department of Mathematics and Science Education, 28100, Giresun, TURKEY \\ ${ }^{\boldsymbol{b}}$ Giresun University, Vocational High School of Giresun, Debboy Location, 28049, Giresun, TURKEY \\ ${ }^{c}$ Giresun University, Central Research Laboratory, Güre Location, 28100, Giresun, TURKEY
}

\section{ARTICLE INFO}

Research Article DOI: 10.15832/ankutbd.471854

Corresponding Author: Ümit ŞENGÜL, E-mail: usengul555@gmail.com, Tel: +90 (454) 3101277

Received: 06 October 2017, Received in Revised Form: 04 December 2017, Accepted: 21 December 2017

\begin{abstract}
In this study, the issue of whether the aflatoxin in high contaminated hazelnut has been passed to the hazelnut oil during production or not has been investigated. The oil and oil cake of the hazelnut samples that contained aflatoxin at a high level were obtained for the study. The aflatoxin concentrations in hazelnut, hazelnut oil and oil cake were measured, and how much of the aflatoxin in the hazelnut was passed into the oil and oil cake has been determined. Aflatoxin analysis was performed using AOAC (Association of Official Analytical Chemists Method): 991.31 method, which is one of the validated method used in aflatoxin analysis in hazelnuts. The highest aflatoxin concentration in hazelnut oil has been determined as AFB1: 0.93, AFG1: 0.52, AFB2: 0.47 and AFG2: $0.21 \mu \mathrm{g} \mathrm{kg}{ }^{-1}$. At the end of the study, it was determined that although the hazelnuts of which the hazelnut oil was obtained contained aflatoxin at a very high level, it was passed to the oil at very low levels below the maximum limits defined by the European Union, and almost all of it remained in the oil cake. Aflatoxin in hazelnut is passed to hazelnut oil at very low amount.
\end{abstract}

Keywords: Aflatoxin; Hazelnut; Hazelnut oil; Hazelnut oil cake

(C) Ankara Üniversitesi Ziraat Fakültesi

\section{Introduction}

Hazelnut (Corylus avellana L.) is cultivated on the coast of the Black Sea of Turkey and in Southern Europe. Turkey is the biggest producer of hazelnut in the world, accounting for $75 \%$ of total world production (Aktaş et al 2011; Baltac1 et al 2012). Hazelnut contains sterols, tannins, essentials minerals, free phenolic acids, sugars, organic acids and phenolic compound. Additionally, hazelnut contains tocopherols and other bioactive polyphenols, which exhibit a beneficial effect on human health, reducing oxidative stress and risk of cancer, stroke, inflammation, and other neurodegenerative diseases (Schmitzer et al 2011). It has a rich nutritional source with $65 \%$ oil, $14 \%$ protein, and $16 \%$ carbohydrates. More than $90 \%$ of its oil consists of unsaturated fatty acids, especially oleic $\left(\mathrm{C}_{18: 1}, 80 \%\right)$ and linoleic $\left(\mathrm{C}_{18: 2}, 12 \%\right)$ acids (Özkal et al 2005). Hazelnut is also used in production hazelnut oil due to the high fat content. Hazelnut oil is also used for several purposes such as cooking, salad dressings, and flavoring ingredients, 
among others. Hazelnut fatty acid composition is very similar to that of olive oil. Oleic (C 18:1) and linoleic (C 18:2) are the main fatty acids in both oils (Parcerisa et al 2000). Hazelnut oil also containedtwo to three times more $\alpha$-tocopherol than olive oil (Benitez-Sánchez et al 2003; Alaşalvar et al 2009).

The contamination of foodstuffs with aflatoxin is a major problem worldwide. Keeping food and feed ingredients away from mould is one of the major difficulties encountered in cultivated areas, especially in humid regions. The Black Sea Region is an area with high rainfall and a climate that is hot in summer and warm in winter. This feature increases the growth of mould in food.

Mycotoxins are those secondary metabolites of fungi which are associated with certain disorders in animals and humans (D'Mello \& Macdonald 1997). Aflatoxins (AFs) are considered one of the main types of mycotoxins produced by different species of toxigenic fungi, especially Aspergillus flavusand, Aspergillus parasiticus species. The most important aflatoxin types are aflatoxin B1 (AFB1), B2 (AFB2), G1 (AFG1), G2 (AFG2), M1 (AFM1) and M2 (AFM2). Among them, AFB1 shows the highest toxicity (Milhome et al 2014; Özlüoymak 2014; Asghar et al 2016). Mycotoxin contaminated grains and oil seeds are toxic and carcinogenic to humans and animals. The primary target organ of aflatoxin in toxicity and carcinogenicity with acute toxicity, immunosuppressive, mutagenic, teratogenicity and carcinogenic properties is the liver (Binder et al 2007). Informing producers and consumers that aflatoxin causes serious health problems is vital. The European Commission has set maximum permissible limits $10 \mu \mathrm{g} \mathrm{kg}^{-1}$ for total aflatoxin and $5 \mu \mathrm{g} \mathrm{kg}^{-1}$ for AFB1 in hazelnut (EC 2010). Informing producers and consumers that aflatoxin causes serious health problems is vital.

Hazelnut grows in wet and humid climatic conditions. Adverse climatic conditions result in the formation of aflatoxin in hazelnuts during the harvesting, drying and storing processes (Miletic et al 2009; Lavkor \& Biçici 2015). Studies into contamination of aflatoxin in nuts and nut products in literature have accelerated with the detection of aflatoxin and aflatoxigenic moulds (Aycicek et al 2005; Gürses 2006; Bircan et al 2008; Basaran \& Ozcan 2009; Baltac1 et al 2012). Numerous studies have reported high incidence of aflatoxins contamination in edible oils such as olive oil (Daradimos et al 2000; Papachristou \& Markaki 2004; Cavaliere et al 2007; Ferracane et al 2007), peanut oil (Elzupir et al 2010; Yang et al 2011), sesame oil (Elzupir et al 2010; Idris et al 2010), blended oil (Yang et al 2011), groundnut (Idris et al 2010; Mariod \& Idris 2015), cottonseed oils (Idris et al 2010) and sunflower (Elzupir et al 2010; Mariod \& Idris 2015) in worldwide.

Studies on aflatoxin in hazelnut oil are inadequate in Turkey and in other countries. The use of hazelnut oil as edible oil is becoming widespread as an alternative to olive oil in terms of the nutrients it contains. Hazelnuts that are not sold or consumed in the market are generally preferred for oil production. The probability of the existence of aflatoxin is high in these hazelnuts. The purpose of this study is to determine the rate of the aflatoxin that is passed to oil during the production of hazelnut oil, and to determine the amount of aflatoxin that remains in the oil cake after production.

\section{Material and Methods}

\subsection{Materials and reagents}

Methanol, acetonitrile (ACN), hexane, nitric acid $65 \%$, potassium bromide and sodium chloride HPLC graded and purchased from Merck (Darmstadt, Germany). Immunoaffinity columns (Aflaprep P07) with $1 \mathrm{~mL}$ volume were purchased from R-Biopharm Rhone Ltd. (Darmstadt, Germany). Standard solution of aflatoxin (Aflastandard, R-Biopharm) was used in the preparation of calibration curves and recovery experiments. The stock standard of aflatoxin is sold as a $1000 \mathrm{ng} \mathrm{mL}^{-1}$ concentration of a methanol solution. It consists of $250 \mathrm{ng} \mathrm{mL}^{-1}$ AFG1, AFG2, AFB1, and AFB2 type aflatoxins. Ultra-pure waters was produced by Sartorius Arium Pro VF (Goettingen, Germany). 


\subsection{Samples}

All of five hazelnut samples containing aflatoxin were taken from Food Control Laboratory, Ordu, Turkey. Hazelnut samples of at least $1 \mathrm{~kg}$ were transported to the laboratory in sterile polyethylene bags under cold conditions and preserved at $-20{ }^{\circ} \mathrm{C}$ until the experimental process could be conducted. All samples were analysed individually (without subsampling) for aflatoxin content tests. Firstly, aflatoxin analyses were carried out on hazelnut samples. The oils and oil cake of these samples were obtained using hexane in the soxhlet apparatus. Amounts of aflatoxin were determined in the hazelnut oil and oil cake. All experiments were performed with at least three replicates.

\subsection{Aflatoxin analysis and extraction process}

The analysis was performed according to AOAC Official Method 991.31:2000 (AOAC 991:31), which has international validity in aflatoxin analysis (AOAC 1991).

Each of hazelnut, hazelnut oil and oil cake samples $(25 \mathrm{~g})$ were taken in a blender jar, $5 \mathrm{~g}$ of sodium chloride and $125 \mathrm{~mL}$ of ACN/H2O (70:30, $\mathrm{v}: \mathrm{v})$ were added to it. After blended for $2 \mathrm{~min}$ at high speed, the extract was filtered through Whatman No. 4 filter paper (Whatman International, Maidstone, UK). $15 \mathrm{~mL}$ was removed and $30 \mathrm{~mL}$ of water was added. It was mixed thoroughly and the extract was filtered through Whatman No. 4 filter paper. Finally, $15 \mathrm{~mL}$ of the reconstituted extract were passed through the Immunoaffinity columns (IAC) at a flow rate of $2 \mathrm{~mL} \mathrm{~min}^{-1}$. After passed to two aliquots of 10 $\mathrm{mL}$ ultrapure water through the column, AFs bound to the specific antibody were slowly released using $1 \mathrm{~mL}$ of methanol and diluted with $1 \mathrm{~mL}$ ultrapure water in HPLC vials. Vital was fully mixed in Vortex and made suitable for the high-performance liquid chromatography (HPCL).

\subsection{Instrument and chromatographic conditions}

Analysis was performed using a HPLC 1100 series (Agilent Technologies, Barcelona, Spain) fitted with an auto-sampler and a fluorescence detector operated at an excitation wavelength, of $360 \mathrm{~nm}$ and emission wavelength of $430 \mathrm{~nm}$. HPLC mobile phase was a mixture of water-acetonitrile-methanol $(6: 2: 3, v: v: v)$ with a flow rate of $1.0 \mathrm{~mL} \mathrm{~min}^{-1}$. The chromatographic reverse phase HPLC separation was performed on a ODS-2 column. Column temperature was $25{ }^{\circ} \mathrm{C}$. The injection volume was $100 \mu \mathrm{L}$.

\subsection{Validation of the analytical method}

In the analysis of hazelnut, hazelnut oil and oil cake samples, the method of AOAC 991.31 that is a valid method in aflatoxin analysis was used (AOAC 1991). The retention times of the standard and samples were respectively AFB1, AFB2, AFG1 and AFG2, 14.5 min., 12.2 min., $10.6 \mathrm{~min}$ and 9.0 min. with $2 \%$ standard deviation. Peaks were found to be quite symmetrical and sharp. There was no interference.

\subsubsection{Linearity}

Linearity was estimated by diluting the total aflatoxin standard stock solutions at concentrations of $0.10,0.50,1.0,2.5,5.0,10.0$ and $20.0 \mathrm{ng} \mathrm{mL}^{-1}$. The concentration of the samples is within the range of calibration. Samples exceeded the calibration range were reread by being diluted. Linear correlation coefficient $\left(\mathrm{R}^{2}\right)$ was found above 0.999 for all aflatoxin types. The residual standard deviation (RSD) values were below $1 \%$. The values of the calibration curves are shown in Table 1.

Table 1- Summary of calibration curve parameters

\begin{tabular}{llll}
\hline Aflatoxin & Regression equation & $R^{2}$ & $R S D \%$ \\
\hline AFG2 & $\mathrm{Y}=6.67775 \mathrm{x}-1.82801 \mathrm{e}^{-1}$ & 0.99941 & 0.38583 \\
AFG1 & $\mathrm{Y}=6.44608 \mathrm{x}-2.05951 \mathrm{e}^{-1}$ & 0.99967 & 0.26338 \\
AFB2 & $\mathrm{Y}=11.43629 \mathrm{x}-1.36371 \mathrm{e}^{-2}$ & 0.99916 & 0.47764 \\
AFB1 & $\mathrm{Y}=8.85254 \mathrm{x}-1.77944 \mathrm{e}^{-1}$ & 0.99957 & 0.41328 \\
\hline
\end{tabular}

$\mathrm{R}^{2}$, linear correlation coefficient; RSD, residual standard deviation

\subsubsection{Accuracy and precision}

Recovery, repeatability analysis was conducted in a hazelnut oil sample that did not contain toxin by adding standard addition from aflatoxin obtained from R-Biopharm Rhone that were spiked with $0.5,1.0$ and $2.5 \mu \mathrm{g} \mathrm{kg}^{-1}$ of each aflatoxin. All spike 
samples were kept at room temperature for at least 1 hour before analysis. Spike samples were studied as three parallels and three injections each (ICH 2006). From this point, the recovery was calculated and the accuracy of method was found according to Equation 1. Repeatability was used for precision, and the relative standard deviation (RSD) of the results was calculated according to Equation 2 and repeatability was found. Recovery rates ranged from $90.7-102.6 \%$ as AFG1>AFB1>AFG2>AFB2.
These values are within the acceptable values of AOAC and the Codex Alimentarius. The AOAC guideline for the acceptable recovery at the $10 \mu \mathrm{g}$ $\mathrm{kg}^{-1}$ level is $70-125 \%$ and the Codex acceptable recovery range is $70-110 \%$ for a level of $10-100 \mu \mathrm{g}$ $\mathrm{kg}^{-1}$, and $60-120 \%$ for a level of $1-10 \mu \mathrm{g} \mathrm{kg}^{-1}$ (Codex Alimentarius 1993; AOAC 2013). RSD percentage values were quite low. These results show that this method is suitable for aflatoxin analysis in hazelnut samples.

Recovery $(\%)=($ Recovered concentration $/$ Infected concentration $) x 100$

Relative standard deviation $(\%)=($ Standard deviation $/$ Mean $) \times 100$

\subsubsection{Limit of detection (LOD) and limit of quantification (LOQ)}

Limit of detection (LOD) and limit of quantification (LOQ) were calculated according to signal to noise $(\mathrm{S} / \mathrm{N})$ method. LOD and LOQ determined as signal to noise $(\mathrm{S} / \mathrm{N})$ ratio of 3 and 10 respectively (Şengül 2016). The results of repeatability, recovery, LOD and LOQ are given in Table 2.

\section{Results and Discussion}

In this study, five hazelnut samples that contained aflatoxin at high levels were examined. The oil was extracted from each hazelnut sample and the oil, oil cake and hazelnut samples were determined for aflatoxin existence by HPLC. The analyses were made in accordance with the AOAC 991:31, which is a validated method (AOAC 1991). Aflatoxin

Table 2- Validation studies in hazelnut oil samples

\begin{tabular}{|c|c|c|c|c|c|c|}
\hline Aflatoxin & $\begin{array}{l}\text { Spiking level } \\
\left(\mu g \mathrm{~kg}^{-1}\right)\end{array}$ & $\begin{array}{l}\text { Repeatability } \\
\left(\text { mean } \pm S D^{a}\right) \\
\left(\mu g \mathrm{~kg}^{-1}\right)\end{array}$ & $\begin{array}{l}\text { Recovery (\%) } \\
(\text { mean } \pm S D)\end{array}$ & $\begin{array}{c}R S D_{R}^{b} \\
(\%)\end{array}$ & $\begin{array}{c}L O D \\
\left(\mu g \mathrm{~kg}^{-1}\right)\end{array}$ & $\begin{array}{c}L O Q \\
\left(\mu g \mathrm{~kg}^{-1}\right)\end{array}$ \\
\hline AFG2 & $\begin{array}{l}0.50 \\
1.00 \\
2.50\end{array}$ & $\begin{array}{l}0.443 \pm 0.012 \\
0.749 \pm 0.013 \\
1.892 \pm 0.102\end{array}$ & $\begin{array}{l}88.58 \pm 2.42 \\
74.87 \pm 1.30 \\
75.68 \pm 4.09\end{array}$ & $\begin{array}{l}2.74 \\
1.74 \\
5.40\end{array}$ & 0.0492 & 0.1642 \\
\hline AFG1 & $\begin{array}{l}0.50 \\
1.00 \\
2.50\end{array}$ & $\begin{array}{l}0.409 \pm 0.015 \\
0.710 \pm 0.011 \\
1.870 \pm 0.026\end{array}$ & $\begin{array}{l}81.87 \pm 3.02 \\
70.97 \pm 1.15 \\
74.81 \pm 1.04\end{array}$ & $\begin{array}{l}3.69 \\
1.63 \\
1.39\end{array}$ & 0.0528 & 0.1761 \\
\hline AFB2 & $\begin{array}{l}0.50 \\
1.00 \\
2.50\end{array}$ & $\begin{array}{l}0.446 \pm 0.017 \\
0.786 \pm 0.005 \\
2.193 \pm 0.052\end{array}$ & $\begin{array}{l}89.22 \pm 3.37 \\
78.63 \pm 0.49 \\
87.73 \pm 2.07\end{array}$ & $\begin{array}{l}3.77 \\
0.62 \\
2.36\end{array}$ & 0.0484 & 0.1615 \\
\hline AFB1 & $\begin{array}{l}0.50 \\
1.00 \\
2.50\end{array}$ & $\begin{array}{l}0.366 \pm 0.020 \\
0.648 \pm 0.007 \\
1.750 \pm 0.016\end{array}$ & $\begin{array}{l}73.27 \pm 3.96 \\
64.85 \pm 0.74 \\
70.00 \pm 0.66\end{array}$ & $\begin{array}{l}5.41 \\
1.15 \\
0.94\end{array}$ & 0.0590 & 0.1968 \\
\hline
\end{tabular}

${ }^{\mathrm{a} S D}$, Standard deviation; ${ }^{\mathrm{b}} \mathrm{RSD}_{\mathrm{R}}$, Relative standard deviation 
results on the samples are shown in Table 3. When the results are examined, it is seen that aflatoxin is passed to the oil at a very low level when the oil was extracted from the hazelnut samples. The highest aflatoxin concentration was detected in the AFG1 among the hazelnut samples analyzed in the study, and AFB1, AFG2 and AFB2 follow this. In the hazelnut oil, the highest concentration was found in AFB1; and AFG1, AFB2 and AFG2 follow this. The rate of the transition of the aflatoxin to the oil is at $5.83 \%$ for $\mathrm{AFB} 2,4.38 \%$ for $\mathrm{AFB} 1,3.44 \%$ for $\mathrm{AFG} 2$ and $1.88 \%$ for AFG1. It was observed that aflatoxin remained in oil cake at a great rate. The maximum aflatoxin concentrations in the analyses of hazelnut oils were as follows; AFB1: 0.93; AFG1: 0.52; AFB2: 0.47; and AFG2: $0.21 \mu \mathrm{g} \mathrm{kg}^{-1}$. When the amount of the aflatoxin in the oil cake was examined, it was observed that the aflatoxin values in the oil cake were very high. Almost all of the aflatoxin remained in the oil cake. We can claim that the aflatoxin in the hazelnut is not passed to the oil and almost all of it remains in the oil cake.

The aflatoxin limits in foods vary according to countries and their economic conditions. According to the European Union, the maximum aflatoxin limits permitted in vegetables oil are $2 \mu \mathrm{g} \mathrm{kg}-1$ AFB1 and 4 $\mu \mathrm{g} \mathrm{kg}^{-1}$ for total aflatoxin (EC 2010). The values that we found in hazelnut oil are below these limit values.

Since no studies were detected in the literature on determining aflatoxin in hazelnut oil, the results were compared with the results of the studies that were conducted to determine aflatoxin in other oils. When the literature results were examined, it is observed that some oil types are contaminated more with aflatoxin.

Table 3- The values aflatoxin in hazelnut, hazelnut oil and hazelnut oil cakes samples

\begin{tabular}{|c|c|c|c|c|c|c|c|}
\hline \multirow[t]{2}{*}{$\begin{array}{l}\text { Sample } \\
\text { no }\end{array}$} & & \multicolumn{2}{|l|}{$\begin{array}{l}\text { Hazelnut } \\
\left(\mu g \mathrm{~kg}^{-1}\right)\end{array}$} & \multicolumn{2}{|l|}{$\begin{array}{l}\text { Hazelnut oil } \\
\left(\mu g \mathrm{~kg}^{-1}\right)\end{array}$} & \multicolumn{2}{|c|}{$\begin{array}{l}\text { Hazelnut oil cake } \\
\left(\mu g \mathrm{~kg}^{-1}\right)\end{array}$} \\
\hline & & $m e a n \pm S D$ & $R S D$ & $m e a n \pm S D$ & $R S D$ & $m e a n \pm S D$ & $R S D$ \\
\hline \multirow[t]{4}{*}{1} & G2 & $5.88 \pm 0.230$ & 3.98 & LOD & - & $5.79 \pm 0.013$ & 0.22 \\
\hline & G1 & $20.65 \pm 0.360$ & 1.76 & $0.32 \pm 0.006$ & 1.86 & $18.70 \pm 0.082$ & 0.44 \\
\hline & B2 & $6.37 \pm 0.120$ & 1.85 & $0.36 \pm 0.005$ & 1.44 & $6.17 \pm 0.050$ & 0.81 \\
\hline & B1 & $18.61 \pm 0.588$ & 3.18 & $0.60 \pm 0.006$ & 1.05 & $15.49 \pm 0.181$ & 1.17 \\
\hline \multirow[t]{4}{*}{2} & G2 & $5.83 \pm 0.423$ & 7.28 & LOD & - & $5.58 \pm 0.020$ & 0.44 \\
\hline & G1 & $35.32 \pm 0.579$ & 1.66 & $0.11 \pm 0.019$ & 17.20 & $33.69 \pm 0.130$ & 0.40 \\
\hline & B2 & $3.32 \pm 0.191$ & 5.77 & $0.03 \pm 0.001$ & 3.58 & $3.29 \pm 0.050$ & 1.58 \\
\hline & B1 & $17.63 \pm 0.362$ & 2.03 & $0.20 \pm 0.016$ & 8.13 & $15.34 \pm 0.441$ & 2.88 \\
\hline \multirow[t]{4}{*}{3} & G2 & $9.27 \pm 0.251$ & 2.73 & $0.32 \pm 0.006$ & 1.97 & $7.15 \pm 0.106$ & 1.47 \\
\hline & G1 & $28.07 \pm 1.187$ & 4.24 & $0.52 \pm 0.003$ & 0.61 & $23.33 \pm 0.352$ & 1.49 \\
\hline & B2 & $8.02 \pm 0341$ & 4.29 & $0.47 \pm 0.008$ & 1.73 & $7.66 \pm 0.154$ & 2.00 \\
\hline & B1 & $21.31 \pm 0.912$ & 4.25 & $0.93 \pm 0.012$ & 1.30 & $17.20 \pm 0.414$ & 2.39 \\
\hline \multirow[t]{4}{*}{4} & G2 & $7.13 \pm 0.185$ & 2.51 & LOD & - & $5.70 \pm 1.189$ & 20.95 \\
\hline & G1 & $42.23 \pm 2.422$ & 5.73 & $0.06 \pm 0.008$ & 12.14 & $39.71 \pm 7.163$ & 18.04 \\
\hline & B2 & $3.85 \pm 0.021$ & 0.51 & $0.02 \pm 0.004$ & 28.78 & $3.64 \pm 0.680$ & 18.72 \\
\hline & B1 & $20.46 \pm 0.404$ & 1.96 & $0.09 \pm 0.002$ & 2.52 & $19.63 \pm 3.492$ & 17.76 \\
\hline \multirow[t]{4}{*}{5} & G2 & $6.06 \pm 0.090$ & 1.41 & $0.21 \pm 0.061$ & 29.10 & $4.20 \pm 0.332$ & 7.75 \\
\hline & G1 & $17.84 \pm 0.342$ & 1.87 & $0.34 \pm 0.033$ & 9.77 & $16.30 \pm 1.771$ & 10.88 \\
\hline & B2 & $5.59 \pm 0.330$ & 5.91 & $0.33 \pm 0.024$ & 7.36 & $4.94 \pm 0.520$ & 10.57 \\
\hline & B1 & $14.59 \pm 0.871$ & 5.98 & $0.51 \pm 0.075$ & 14.70 & $14.39 \pm 1.512$ & 10.50 \\
\hline
\end{tabular}


Similar findings were observed in olive oil samples. Ferracane et al (2007), found the presence of AFB1 only 3 out of 30 samples were contaminated ranging from 0.54 to $2.50 \mu \mathrm{g} \mathrm{kg}^{-1}$ in olive oil (Ferracane et al 2007). Additionally, Papachristou \& Markaki (2004), who studied 50 samples and $60 \mathrm{ng} \mathrm{kg}^{-1}$ of AFB1 was found only one of them (Papachristou \& Markaki 2004). Daramidos et al (2000) determined AFB1 in 2.8-15.7 $\mathrm{ng} \mathrm{kg}^{-1}$ of the concentration range in $72 \%$ of 50 olive oil samples. However one sample was contaminated with $46.3 \mathrm{ng} \mathrm{kg}^{-1}$. In 14 samples AFB1 was not detectable (Daramidos et al 2000). Cavalier et al (2007) found that thirty-five olive oil samples were analysed and aflatoxins were not detected (Cavalier et al 2007). As it is observed in these studies, Aflatoxin is observed in a small amount in the olive oil samples, and the highest value reported is $2.5 \mu \mathrm{g}$ $\mathrm{kg}^{-1}$. Aflatoxin is not passed to the oil in olive oil samples, which is the case in hazelnut oil, and exists in very small amounts.

A study was conducted on peanut oil by Yang et al (2011), and the following values were reported for 15 of the 31 samples; AFB1 $\left(0.15-2.72 \mu \mathrm{g} \mathrm{kg}^{-1}\right)$, and for 6 of them as AFB2 $\left(0.15-0.36 \mu \mathrm{g} \mathrm{kg}^{-1}\right)$, and for 3 of them as AFG1 $\left(0.01-0.02 \mu \mathrm{g} \mathrm{kg}^{-1}\right)$. They examined other oils in the same study and AFB1 contamination was recorded in 15 peanut oils, six blended oils and single animal oil (fish oil). However, AFB2 and AFG1 were found only in peanut oil and in no other type of oil (Yang et al 2011). This could indicate that peanut oils are more susceptible to aflatoxin contamination. When compared with our results, AFB1 is the toxin found with the highest level in peanut oil and in the other oils analyzed in this study, as in the case of hazelnut oil. AFG1 was the toxin found at the second highest level in our results. This stems from the fact that the AFG1 amount is high in the hazelnut samples we used in the analyses in our study. It is passed to oil with the lowest level when examined the percentages of passed to oils. AFB types are passed to oil more than other. We may conclude this from the results of the study conducted by Yang et al (2011).
Elzupir et al (2010), conducted a study on a total of 81 vegetable oil samples including peanuts $(\mathrm{n}=$ $21)$, sesame $(n=14)$, and sunflower $(n=19)$. The average concentrations in peanut oil were found to AFB1 as 16.3, AFB2 as 1.0, AFG1 as 12.9 and AFG2 as $11.6 \mu \mathrm{g} \mathrm{kg}^{-1}$ (Elzupir et al 2010). These values are extremely high when compared with the results of our study and other studies. AFB1 is the toxin found with the highest level in this study. However, AFG1 and AFG2 values were also determined to be high. Average levels in sesame oil were found AFB1 as 43.6; AFB2 as 0.3: AFG1 as 47.5 and AFG2 as $102.7 \mu \mathrm{g} \mathrm{kg}^{-1}$. In sunflower oil was detected AFB1 as 24.6, AFB2 as 0.3: AFG1 as 24.5 and AFG2 as $14.8 \mu \mathrm{g} \mathrm{kg}^{-1}$. These values are very different from the results we found in hazelnut oil.

\section{Conclusions}

The hazelnuts that are used in hazelnut oil production industry are the ones that are not sold in the market with low quality. For this reason, it is highly probable that aflatoxin exists much in these hazelnuts. However, the results obtained in the analyses show that aflatoxin is passed to the oil at a very low concentration. Aflatoxin is not passed to oil and is accumulated in the oil cake. This reveals another problem that has to be investigated, because the oil cake of the hazelnuts is used as feed in animal feed industry. For this reason, it has to be investigated for aflatoxin before used in feed industry.

\section{Acknowledgements}

Giresun University Research Fund supported this work (Project No: FEN-BAP-A-220413-38).

\section{References}

Aktaş A, Öztürk E \& Hatırlı S (2011). Türkiye findık tarımında kar etkinsizliğinin analizi. Journal of Agricultural Sciences 17(3): 230-240

Alaşalvar C, Amaral J S, Satır G \& Shahidi F (2009). Lipid characteristics and essential minerals of native Turkish hazelnut varieties (corylus avellana L.). Food Chemistry 113(4): 919-925 
Alaşalvar C, Shahidi F, Amaral, J S \& Oliveira B P P (2009). Compositional characteristics and health effects of hazelnut (Corylus avellana L.): An overview. In C Alasalvar \& F Shahidi (Eds.), Treenuts: Compositions, phytochemicals, and health effects. Boca Raton, FL: CRC Press Taylor \& Francis Group, pp. 185-214

Asghar M, Ahmed A, Iqbal J, Zahir E \& Nauman H (2016). Fungal flora and aflatoxin contamination in Pakistani wheat kernels (Triticum aestivum L.) and their attribution in seed germination. Journal of Food and Drug Analysis 24: 635-643

AOAC (1991). Association of Official Analytical Chemists. Official method 991.31. Aflatoxins in maize, raw peanuts and peanut butter (immunoaffinity column method). Journal of AOAC International 74: $81-88$

AOAC (2013). Association of Official Analytical Chemists. Guidelines for dietary supplements and botanicals. Appendix K, p. 8. AOAC International, Gaithersburg, MD, USA. Retrieved in January, 23, 2016 from http://www.eoma.aoac.org/app_k.pdf

Ayçiçek H, Aksoy A \& Sayg1 S (2005). Determination of aflatoxin levels in some dairy and food products which consumed in Ankara, Turkey. Food Control 16(3): 263-266

Baltacı C, İlyasoğlu H \& Cavrar S (2012). Aflatoxin levels in raw and processed hazelnuts in Turkey. Food Additives and Contaminants: Part B Surveillance 5(2): 83-86

Başaran P \& Özcan M (2009). Occurrence of aflatoxıns in various nuts commercialized in Turkey. Journal of Food Safety 29: 95-105

Benitez-Sánchez P, León-Camacho M \& Aparicio R (2003). A comprehensive study of hazelnut oil composition with comparisons to other vegetable oils, particularly olive oil. European Food Research and Technology 218(1): 13-19

Binder E, Handl J, Tan L, Chin L \& Richard J (2007). Worldwide occurrence of mycotoxins in commodities, feeds and feed ingredients. Animal Feed Science and Technology 137(3-4): 265-282

Bircan C, Barringer S, Ülken Ü \& Pehlivan R (2008). Aflatoxin levels in dried figs, nuts and paprika for export from Turkey. International Journal of Food Science \& Technology 43(8): 1492-1498

Cavaliere C, Foglia P, Guarino C, Nazzari M, Samperi $R$ \& Laganà A (2007). Determination of aflatoxins in olive oil by liquid chromatography-tandem mass spectrometry. Analytica Chimica Acta 596(1): 141148

Codex Alimentarius (1993). Pesticide residues in food Vol. 2. FAO/WHO, Rome, Italy

Daradimos E, Marcaki P \& Koupparis M (2000). Evaluation and validation of two fluorometric HPLC methods for the determination of aflatoxin B1 in olive oil. Food Additives and Contaminants 17(1): 65-73

D’Mello J P F \& Macdonald A M C (1997). Mycotoxins. Animal Feed Science and Technology 69(1): 155-166

EC (European Commission Regulation) (2010). EC No. 165/2010 of 26 February 2010. Amending Regulation (EC) No 1881/2006 setting maximum levels for certain contaminants in foodstuffs as regards aflatoxins. Official Journal of the European Union, EU publication, L 50/8

Elzupir A, Elhussein A, Suliman M, Ibrahim I \& Fadul M (2010). Aflatoxins levels in vegetable oils in Khartoum State, Sudan. Mycotoxin Research 26(2): 69-73

Ferracane R, Tafuri A, Logieco A, Galvano F, Balzano D \& Ritieni A (2007). Simultaneous determination of aflatoxin B1 and ochratoxin A and their natural occurrence in Mediterranean virgin olive oil. Food Additives and Contaminants 24(2): 173-180

Gürses M (2006). Mycoflora and aflatoxin content of hazelnuts, walnuts, peanuts, almonds and roasted chickpeas (LEBLEBI) sold in Turkey. International Journal of Food Properties 9(3): 395-399

$\mathrm{ICH}$ (International Conference on Harmonization) (2006). Harmonized tripartite guideline, validation of analytical procedures, text and methodology. ICH Q2R1, 12e4

Idris Y, Mariod A, Elnour I \& Mohamed A (2010). Determination of aflatoxin levels in Sudanese edible oils. Food and Chemical Toxicology 48: 2539-2541

Lavkor I \& Biçici M (2015). Osmaniye'de yetiştirilen yerfistıklarında hasat, hasat sonrası, kurutma ve depo öncesi dönemlerinde aflatoksin oluşumu. Journal of Agricultural Sciences 21(3): 394-405

Mariod A \& Idris Y (2015). Aflatoxin B1 levels in groundnut and sunflower oils in different Sudanese states. Food Additives and Contaminants: Part B Surveillance 8(4): 266-270 
Miletic R, Mitrovic M \& Rakicevic M (2009). Contrasting fruit properties of hazelnut cultivars grown on different rootstocks. Acta Hortic 845: 283-286

Milhome M, Lima C, de Lima L, Lima F, Sousa D \& Nascimento R (2014). Occurrence of aflatoxins in cashew nuts produced in northeastern Brazil. Food Control 42: 34-37

Özkal S G, Salgın U \& Yener M E (2005). Super critical carbondioxide extraction of hazelnut oil. Journal of Food Engineering 69(2): 217-223

Özlüoymak Ö B (2014). Development of a UV-based imaging system for real-time detection and separation of dried figs contaminated with aflatoxins. Journal of Agricultural Sciences 20(3): 302-316

Papachristou A \& Markaki P (2004). Determination of ochratoxin A in virgin olive oils of Greek origin by immunoaffinity column clean-up and highperformance liquid chromatography. Food Additives and Contaminants 21(1): 85-92
Parcerisa J, Casals I, Boatella J, Codony R \& Rafecas M (2000). Analysis of olive and hazelnut oil mixtures by high-performanceliquid chromatography-atmospheric pressure chemica ionisation mass spectrometry of triacylglycerols and gas-liquidchromatography of non-saponifiable compounds (tocopherolsandsterols). Journal of Chromatography A 881(1): 149-158

Schmitzer V, Slatnar A, Veberic R, Stampar F \& Solar A (2011). Roasting affects phenolic composition and antioxidative activity of hazelnuts (Corylus avellana L.). Journal of Food Science 76(1): 9-14

Şengül Ü (2016). Comparing determination methods of detection and quantification limits for aflatoxin analysis in hazelnut. Journal of Food and Drug Analysis 24(1): 56-62

Yang L, Liu Y, Miao H, Dong B, Yang N, Chang F, Yang L \& Sun J (2011). Determination of aflatoxins in edible oil from markets in Hebei Province of China by liquid chromatography-tandem mass spectrometry. Food Additives \& Contaminants: Part B: Surveillance Communications 4(4): 244-247 